\title{
К вопросу о страдательном залоге в языках, распространенных на берегу Балтийского моря, с акцентом на севернорусском диалекте
}

\author{
АРПАД ОРОС \\ BGE PSZK Pénzügyi és Gazdálkodási Szaknyelvek Tanszék, \\ H-1149 Budapest, Buzogány u. 10-12. \\ E-mail: orosz.arpad@uni-bge.hu
}

(Received: 16 August 2019; accepted: 7 November 2019)

1. В общих терминах можно утверждать, что в любом языке мира синтаксические категории подлежащего и (прямого) дополнения являются отвлеченными, потому что они могут соответствовать целому ряду семантических категорий. При этом не вызывает сомнения, что для формирования страдательных структур подлежащее как самостоятельное и довольно отвлеченное грамматическое понятие, независимое от понятия субъекта или агенса как понятия семантического, должно выделиться в самостоятельную категорию. Выделение категории подлежащего в самостоятельную, лексически не ограниченную категорию, как мы это видим в случае английского языка, связано и с появлением более сильного центра функционально-семантического поля (ФСП) залоговости (БондАРко 1991). В данном случае усиление центра ФСП залоговости проявляется в существовании лишь одного единственного способа выражения пассивного залога.

Как известно, в английском языке страдательные конструкции являются аналитическими формами: они состоят из связки $b e$ 'быть' и причастия прошедшего времени. Это и есть, в основном, единственная возможность выражения страдательного значения, если не принимать во внимание способы лексические, находящиеся дальше от центра ФСП данной категории. В отличие от английского языка, как известно, в русском языке существует два грамматических способа выражения страдательного значения: наряду с аналитическим способом мы встречаем и синтетический способ, выражаемый глаголами с постфиксом -ся. Поскольку глаголы с упомянутым постфиксом -ся обладают широким диапазоном грамматических и лексических значений, а грамматическое значение страдательности переплетается и с единичными значениями лексического характера, центр трактуемого ФСП однозначно ослабевает. Побочно заметим, что страдательное значение в венгерском языке может выражаться тремя грамматическими способами, и лексическая ограниченность подлежащего проявляется приблизительно в такой же степени, как и в русском языке. 
1.1. При этом семантические свойства разных типов подлежащего могут в значительной мере различаться. В нижеприведенных примерах из русского и венгерского языков различие проявляется в диатезных отношениях. Дело в том, что критерии истинности предложений (1a) и (1b) не совпадают, в то время как они совпадают в случае предложений (2a) и (2b) как в русском, так и в венгерском языках. Хотя слова лесоруб и ветер в обоих предложениях выступают в качестве подлежащего, первое является производителем действия, а его референт сознательно действующим лицом, т. е. субъектом, способным контролировать ход событий, поэтому предложение (1a) действительного залога и (1b) не могут быть одновременно истинными, так как (1b) имеет в своем составе возвратный глагол, описывающий спонтанный процесс, в данном случае - спонтанное происшествие. В это же время референт подлежащего в предложении (2a) является естественной силой, неспособной контролировать ход событий, поэтому данное предложение и предложение $2 b[=(1 b)]$ могут быть одновременно истинными, и в подавляющем большинстве случаев они даже оказываются синонимичными. Вслед за другими исследователями мы можем сделать вывод, что очень много зависит от способности референта того или иного лексического элемента контролировать процесс, описываемый предложением, при функционировании данного элемента как подлежащего предложения (KLAIMAN 1988, KLAIMAN 1991).

(1a) Лесоруб повалил дерево. - A favágó kidöntötte a fát.

(1b) Дерево повалилось. - A fa kidölt.

(2a) Ветер повалил дерево. - A szél kidöntötte a fát.

(2b) Дерево повалилось. - A fa kidölt.

1.2. Вышеупомянутые примеры свидетельствуют о том, что синтаксическая категория подлежащего в русском и венгерском языках достигла определенного уровня самостоятельности, потому что подлежащее в этих языках не всегда обладает качествами сознательно действующего лица. В английском языке, где, как было отмечено выше, грамматическая категория залога является однозначным, имеющим лишь один морфологический способ образования, категория подлежащего достигла более высокого уровня самостоятельности. Если взять английские предложения со значением 'Миллионы умирают от рака ежегодно', 'Вчера начальник радовался обручению своей дочери' и 'Брак может быть ужасным из-за неверности одного из супругов', в них слова, обозначающие 'рак', 'обручение' и 'неверность', могут свободно выступать как синтаксическое подлежащее, в то время как соответствующие русские (и также венгерские) предложения хотя и могут иметь эти слова как подлежащее в своем составе, но они не благозвучны, и носители русского и венгерского языков скорее приписывают существование подобных примеров влиянию английского языка.

2.1. В русском языке наблюдается дополнительное распределение глагольных форм с суффиксом $-H /-m$ и с постфиксом $-c я$, потому что ни одна форма не сочетается с обоими аффиксами одновременно. Хотя встречаются 
случаи, когда словоформы с приведенными постфиксом и аффиксом составляют одну парадигму, т. е. они являются разными формами одной лексемы, ни одна словоформа не сочетается с обоими аффиксами одновременно, ср.:

(3a) Maша часто огорчается.

(3b) Маша огорчилась.

(3c) Маша огорчена.

(4а) Иван легко расстраивается.

(4b) Иван очень расстроился.

(4c) Иван очень расстроен.

(5а) Дверь открывается.

(5b) Дверь открылась.

(5c) Дверь открыта.

(6а) Яички мальчиков опускаются не сразу после рождения.

(6b) У него яички опустились слишком рано.

(6c) У трехлетнего мальчика яички уже опущень.

(7а) Шельф вокруг Антарктиды нередко погружается.

(7b) Шельф погрузился.

(7c) Шельф погружен.

Опираясь на обстоятельный анализ В. И. Гавриловой, мы сделали вывод, что формы а) выражают допредельную, а формы б) постпредельную фазу процесса, в то время как формы в) выражают состояние после достижения предела (см. ORosz 2002; ср. Г АВРИловА 1975, ГАвРиловА 1978). В упомянутой работе мы воспользовались термином «медиальный залог» по отношению к трактуемым формам, так как они не относятся ни к активу, ни к пассиву. Процессы, описываемые формами на -ся, в большинстве случаев осуществляются без участия действующего лица, без агенса. Заметим, однако, что в упомянутых работах В. И. Гавриловой термин «медиальный залог» употребляется в более конкретном значении.

2.2. В севернорусском диалекте вышеприведенное дополнительное распределение явно нарушается, так как возвратные глаголы могут иметь в своем составе как постфикс -ся, так и суффикс $-\mu /-m$ :

(8) Чай можно цельй день пить, только уж напитось;

(9) У меня выспанось-то теперь;

(10) У меня было побеспокоенось;

(11) Записанось ли у их, нет ли-может, и не записанось;

(12) У меня не одетось (КузьминА-НЕмченко 1971: 114-115).

Данное обстоятельство, т. е. отсутствие дополнительной дистрибуции вышеприведенных аффиксов, свидетельствует о том, что глагольные формы с суффиксом выражают в этих примерах не состояние, а действие. Причастие с суффиксом $-н /-m$ в этих говорах имеет предикативную функцию, оно выражает не относительное, как в общерусском языке, а прямое время, время прошедшее с перфектным значением. Связка быть в ненулевой форме, 
как в примере $У$ меня было побеспокоенось придает предложению аористическое значение, ср.: (В субботу) у меня было побеспокоенось, но (*B субботу) у меня не одетось (Труьинский 1984: 161). Итак, первичное значение данной структуры - это перфектное значение.

2.2.1. Перфектное значение пассива в общерусском языке (как правило, значение заявления новой ситуации) является подтипом акционального значения, или скорее, толкования пассива. Это было нами продемонстрировано в рамках минималистской программы (ORosz 2002: 60-63), отрасли порождающей грамматики. В этой программе грамматические черты проверяются, а языковые элементы переставляются местами и оставляют за собой копии. Дело в том, что в случае статального толкования пассива как время, так и вид определяются связкой, а не главным глаголом, в то время как в случае акционального толкования пассива только (прямое) время определяется связкой, а вид определяется причастной формой главного глагола. Когда имеется перфектное значение, прямое время определяется нулевой формой связки, а относительное время, как и вид, определяется главным глаголом. Схематически это может быть выражено следующим образом:

Стены были покрамены - статальное толкование

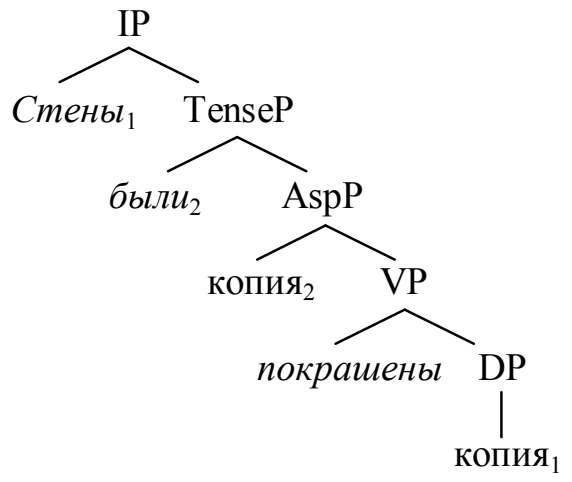

Стены были покрашены - акциональное толкование

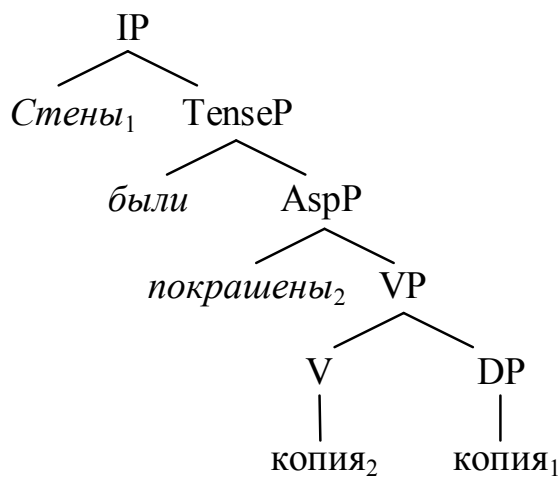


Стены покрашены! - перфектное значение

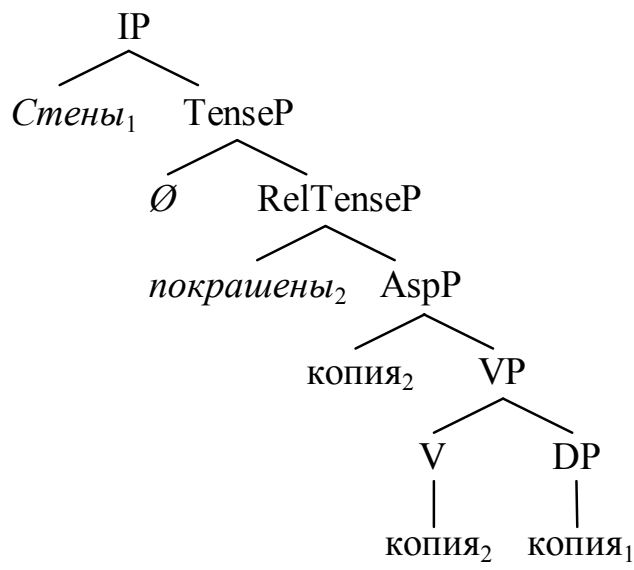

Дело в том, что причастие на $-\mu /-m$ в севернорусских говорах соответствует, в первую очередь, этой последней структуре, когда предложение имеет перфектное значение.

2.3. Следует отметить и деепричастный перфект, также наличествующий в севернорусских говорах, так как в этом случае опять появляется предикативное значение нефинитного глагола. При этом в одной части говоров деепричастный перфект имеет действительное значение, а в другой части говоров - страдательное значение. Примеры первого типа: Он в город приехавши; Девушка писаньем занявши. Примеры последнего типа: Контора заперши; Корова напоивши. Ни в одном из примеров связка быть в прошедшем времени не придает предложению значения простого прошедшего, т. е. значение аористическое (Труьинский 1984: 161). Глаголы, употребляемые в первом типе деепричастного перфекта, являются непереходными глаголами, выражающими изменение состояния или местонахождения производителя действия (ТруБинский 1984: 159). В современном языкознании трактуемый подтип непереходных глаголов имеет название «неаккузативный глагол» и определяется другими словами как непереходный глагол, подлежащее которого имеет тематическую роль пациенса, а не агенса. См. неграмматичность примеров в севернорусских говорах: *Он вспотевши; *Mы все загоревши.

3. Описывая севернорусские говоры более общими и отвлеченными терминами, мы можем заключить, что непереходные глаголы могут поддаваться пассивизации (как это было продемонстрировано выше, так как возвратные глаголы с постфиксом -ся являются непереходными). Помимо этого, мы наблюдаем и другое, на наш взгляд, совсем не независимое явление, заключающееся в том, что при глагольной форме, называющейся в общерусском языке страдательным причастием прошедшего времени, т. е. в структурах с причастиями на $-\mu /-m$, объект действия часто, но не всегда выступает в винительном падеже, т. е. морфологически оформляется как прямое дополнение 
предложения (о морфологическом кодировании синтаксических категорий подлежащего и дополнения см. KEENAN 1976).

Ср. примеры:

(13a) У деда было лисенят поймано;

(13b) Я не очень грамотна - семилетку кончено

(КУзьМИНА-НЕмченКо 1971: 38).

(14а) У нее сварено каша;

(14b) У нее сварено кашу;

(15) У батьки у твоего сажено березку;

(16) У меня было подзаработано стажу (КУЗЬМИНА-НЕМЧЕНКО 1971: 65).

(17) Молоду женщину схвачено медведицей (КУЗЬМИНА-НЕМЧЕНКО 1971: 18).

(18) Редко какая ночь и спана, (мы) не спаты ночь (КУЗЬМИНА-НЕМЧЕНКО 1971: 65).

(19) У их приехано гостей (КУзьМИНА-НЕМЧЕНКО 1971: 18).

(20) Мною езжено (ХРАКОВСКИЙ 1974: 15).

В других языках, расположенных на берегу Балтийского моря, мы встречаемся со сходными явлениями. Здесь имеются в виду сами языки, а не диалекты языков. В общелитовском языке встречаются следующие структуры:

(21) Savo žemę mylèta (Holvoet 2001: 376, SERŽANT 2012: 370). своя страна: ACC.SING любить: PART.PRAET.PASS.NOM.SG.NEUT 'Люди любили свою страну.'

(22) Mano vaihščiota (ХРАКОВСКИЙ 1974: 15). я: GEN ходить: PART.PRAET.PASS.NOM.SG.NEUT 'Я ходил(a).'

В латышском языке вспомогательный глагол выступает в форме действительного причастия прошедшего времени в страдательном предложении:

(23) Māja ir tikusi (uz)celta (Holvoet 2001: 369). дом: Nom.SING быть: PRES.3 AUX.PART.PRAET.ACT.NOM.SG.FEM строить: PART.PRAET.PASS.NOM.SG.FEM 'Дом построен.'

В польском языке объект действия также выступает в винительном падеже при форме страдательного причастия прошедшего времени:

(24) Kiedy analizowano szczegółowo zdjęcia satelitarne, odkryto moła wyspe (OpOC 2002: 109, SERŽANT 2012: 370).

когда анализировать: PART.PRAET.PASS подробно картина: PL.ACC спутниковой: PL.ACC открыть: PART.PRAET.PASS маленький: SG.ACC остров: SG.ACC

'Когда спутниковые картины были подробно анализированы, был открыт небольшой остров.' 
В белорусском языке встречаются конструкции с причастием на $-\mu /-m$ от непереходных глаголов:

(25) Тут скаиінай паходжана (SERŽANT 2012: 375).

здесь скотина: INSTR.SH ходить: PART.PRAET.PASS.NEUTR

'Здесь бывала скотина.'

В нашем распоряжении следующий пример из норвежского языка:

(26) Det ble skutt en ulv (T. Wagener - устное сообщение, 2001).

плеонастическое местоимение связка: PRAET стрелять: PART.PRAET. PASS неопр. артикль волк: SG.ACC

'Волк (был) застрелен.'

3.1. Существуют разные типы объяснений трактуемых явлений, распространенных на берегу Балтийского моря. Наиболее значительными из них мы считаем объяснения американской исследовательницы Б. Дринки и русского ученого И. Сержанта. Первое из них опирается на языковой контакт разных народов в истории европейской культуры. В средние века русские города в северо-западной части России как члены Ганзейского союза торговали с носителями северногерманских языков, и, таким образом, они заимствовали посессивный перфект. Ведь структура « $V+$ род.» в севернорусских говорах, как и в русском языке вообще, выражает посессивность, притяжательность. В западноевропейских языках, например, в английском, немецком и французском и теперь существуют притяжательные структуры, в которых вспомогательные глаголы have, haben, avoir, соответственно, и страдательные причастия прошедшего времени как конструкция выражают перфектное значение, значение, очевидно развившееся из чисто притяжательного значения (DRINKA 2003, DRINKA 2017). Однако И. Сержант подвергает эту гипотезу сомнению. Главными причинами этого сомнения являются следующие соображения: с одной стороны, в упомянутую эпоху, т. е. в начале средних веков существовал конкурс между глаголами иметь и есть, и было бы логично воспользоваться первым из них как глаголом переходным (как все вышеупомянутые вспомогательные глаголы западноевропейских языков являются переходными). С другой стороны, имеются субъекты в творительном падеже, так как данная конструкция и является характерной для пассива в русском языке (SERŽANT 2012: 374-377). См. пример (17): Молоду женшину схвачено медведицей (Кузьмина-Немченко 1971: 18). Существуют также примеры, в которых субъект хотя и стоит в родительном падеже, но выступает не с предлогом $y$, означающим также и притяжательность:

(27) Ей адрес был дано от Вани Гришкина (SERŽANT 2012: 376).

3.1.1. Сам И. Сержант придерживается такого мнения, что упомянутые структуры появились при переходе от статального истолкования к акциональному истолкованию пассива (SERŽANT 2012, SERŽANt 2013, Orosz 2002). На 
первом этапе перехода, когда конструкция обладала чисто статальным значением и говорилось о результативе (НЕдялков-Яхонтов 1983), причастие на совместимо с производителем действия. Потом, на следующей стадии перехода, когда конструкция приобрела перфектное значение и наряду со статальным выделилось также значение, или скорее, истолкование акциональное, производитель действия выдвинулся на передний план, так как в случае перфекта мыслится уже не только результат действия или процесса, а также само предшествующее действие. На последующей стадии языкового перехода причастная форма приобрела и значение простого прошедшего времени, т. е. значение аористическое наряду с перфектным значением. Как нами было отмечено раньше (Орос 2017: 273, ORosz 2012: 811), и как это вытекает из упомянутого труда И. Сержанта, говорить о страдательном значении как таковом, как о его акциональном, так и о его статальном истолковании, невозможно было до появления акционального истолкования (SERŽANT 2012).

3.1.2. Если подходить к вопросу с объективной точки зрения, то оказывается очевидным, что для решения вопроса о том, является ли второе возражение И. Сержанта выдвинутой Б. Дринкой теории уместным, необходимо продолжить лингвистическое исследование. Ведь высказывается и такое мнение, что конструкция « $Y+$ род.» в севернорусских говорах не просто субъект, а выступает как синтаксическое подлежащее предложения, конечно, без морфологического кодирования. Данный подход является наиболее подробно и четко разработанным и аргументированным в работе А. Тимберлейка (см. TIMBERLAKE 1976). Американский исследователь в своей работе приводит целый ряд доводов из области синтаксиса для иллюстрации того, что в конструкции « $V+$ род.» мы имеем дело с синтаксическим подлежащим. А если это так, то надо еще проверить, насколько субъекты в вышеприведенных примерах (17) и (27) в творительном падеже, а также в родительном падеже, но с предлогом, отличающимся от предлога $V$, соответствуют критериям синтаксического подлежащего для того, чтобы мы могли считать возражение И. Сержанта теории Б. Дринки уместным. Дринка утверждает, что в пользу того, что конструкция « $V+$ род.» в самом деле является подлежащим, и что она в севернорусских говорах, как и соответствующая структура в эстонском языке, являющемся тоже языком, распространенным на берегу Балтийского моря, заимствована из западноевропейских языков, говорит и тот факт, что она выступает, как правило, в начале предложения, несмотря на то, что славянские языки характеризуются свободным порядком слов (DRINKA 2017: 363). На материале, приведенном в работе И. Е. Кузьминой и Е. В. Немченко (см. КузьмИнА-НЕмчЕнко 1971), это замечание не кажется вполне оправданным: в примере (13b) трактуемая конструкция пропущена и производитель действия следует лишь из контекста. Но в большинстве случаев это так. А в предложениях, где подлежащее, или по крайней мере субъект, является ремой, а не темой, например, в случае примера (17) невозможно было бы прибегнуть к конструкции « $У+$ род.» на этих же прагматических основаниях. 
Подводя итоги сказанному, мы приходим к выводу, что возражение объяснению, опирающемуся на языковые контакты между членами Ганзейского союза на основании заменимости « $Y+$ род.» другими формами, еще нуждается в подтверждении.

3.2. Однако в принципе мы сходимся с И. Сержантом на том, что (акциональное или статальное) толкование конкретных конструкций является решающим. Итак, в случае севернорусского диалекта, а также на основе того, как мы понимаем и можем толковать языковые данные других языков трактуемого географического региона, то и в этих языках, когда производитель действия, т. е. субъект выдвинулся на передний план в сложившемся перфектном значении и появилось акциональное истолкование пассива, носители этих языков не были способны отделить понятия субъекта и подлежащего с одной стороны и, если посмотреть на примеры (14b)-(17), (19), (21), (24) и (26), понятия объекта и прямого дополнения с другой. Это связано с тем, что языки, и, как мы это видим, также диалекты отдельных языков, выдвигают разные требования к тому, в каком значении слова могут выступать в функции подлежащего. Иначе говоря, языки обладают своим онтологическим оформлением подлежащего. И. Сержант приводит примеры, свидетельствующие - по всей вероятности - о последнем этапе перехода, зарегистрированном лингвистами, происходящем в настоящее время, точнее, за последние несколько десятилетий, в другой работе (SERŽANT 2013: 297, ср. КузьмИНА-НЕмЧЕНКО 1971: 38). Мы констатируем, что субъект, выступавший в родительном падеже, сочетавшийся с предлогом $y$ может выступать - очевидно при наличии определенных прагматических и фонологических критериев - также в именительном падеже, являющемся характерным и типичным для подлежащего вообще (Орос 2018a: 133). Это встречается в разговорном варианте севернорусского диалекта. Итак, наряду с конструкцией типа (14b) У него армию еще не отслужено, в трактуемом диалекте также встречаем:

(28) А он-еме армию не отслужено.

Мы можем сделать такой вывод, что в примере (28) уже наличествует морфологическое кодирование подлежащего (KEENAN 1976), совпадающего с субъектом, и прямого дополнения, совпадающего с объектом. Данное обстоятельство вполне независимо от морфологии глагола предложения, являющегося его центральным элементом в ряде лингвистических теорий и обладающего способностью определить количество и качество синтаксических и семантических актантов предложения. В частности, предложения (28) $\mathrm{A} \mathrm{oн} \mathrm{-}$ еще армию не отслужено и А он - еще армию не отслужил являются вполне синонимичными для носителей севернорусских говоров. Действительная или страдательная форма глагола не является решающей с точки зрения как морфологии, так и семантики актантов предложения.

3.2.1. Пример из норвежского языка (26) заслуживает внимания с точки зрения объяснения языковых явлений. Во-первых, в этом предложении глагол совсем не выражает посессивность, но объект употребляется в винительном 
падеже, хотя данный падеж вытекает только из постглагольной позиции дополнения. Следовательно, в случае данного примера заимствование посессивного перфекта абсолютно невозможно. Более того, оно невозможно еще и потому, что в норвежском языке как, впрочем, и в германских языках вообще, существует перфект как грамматическая категория.

3.3. Нами уже был затронут вопрос о языковом субстрате в случае языков, распространенных на берегу Балтийского моря (Орос 2017, Орос 2018а, Орос 2018b). Дело в том, что существование древнего языка или диалекта, оказавшего влияние на индоевропейские и финно-угорские языки несколько веков или тысячелетий назад весьма трудно исследовать и доказать. Однако Дринка сама пишет о влиянии финно-угорских языков на индоевропейские языки, распространенные в трактуемом регионе (DRINKA 2017: 354). Вопрос не перестает быть очень увлекательным и он представляет собой чрезвычайно большой вызов для лингвистов.

4. Недостаточная разграниченность диатезных отношений может оказаться связанной с весьма широким диапазоном других явлений, как языковых, так и неязыковых. На основании работ, приведенных нами выше, думается, что дискутируемая в настоящей работе тема переплетается с целым рядом вопросов социологии и культурологии. Ведь особенности языка могут отражать культурные отношения, а различия могут соответствовать культурным различиям между народами или народностями, носителями языков и / или диалектов. Языковеды должны сотрудничать с экспертами вышеупомянутых дисциплин, чтобы раскрыть, например, какие грамматические и семантические категории в какой мере связаны со способностью отдельных элементов контролировать действие, процесс или состояние, описываемое в предложении, а также другие элементы предложения в разных языках региона и в других языках. Мы считаем, что данная неязыковая категория способности контролировать ход событий или процессов оказывает значительное влияние на разные типы языковых категорий. Таким образом, изучение способности лингвистических элементов контролировать ход событий и ее взаимосвязи с другими вопросами лингвистики является одной из последующих задач для языковедов.

\section{Литература}

БОНДАРКО 1991 = БОНДАРКО А. В. (ред.) Теория функииональной грамматики. Персональность. Залоговость. Санкт-Петербург: «Наука», 1991.

ГАВРИЛОВА $1975=$ ГАВРИЛОВА В. И. Особенности семантики, синтаксиса и морфологии глаголов присоединения. В кн.: Семиотика и информатика. Вып. 6. Грамматические и семантические проблемы. Москва: «Наука», 1975. 144-164.

ГАВРИЛОВА $1978=$ ГАВРилОВА В. И. К вопросу о выражении диатезы типа «объектный квазипассив» в русском языке. В кн.: Проблемы теории грамматического залога. Ленинград: «Наука», 1978. 203-208.

КуЗьМИНА-НЕМЧЕНКО 1971 = КузьМИНА И. Е., НЕМЧЕНКО Е. В. Синтаксис причастных форм в русских говорах. Москва: «Наука», 1971. 
НЕДЯлков-Яхонтов 1983 = НЕдялков В. П., Яхонтов С. Е. Типология результативных конструкций. В кн.: Типология результативных конструкций. Ленинград: «Наука», 1983. 7-35.

ОРОс 2001 = ОРос А. О генезисе статального пассива и о различии пассивных форм НСВ и СВ в русском языке. Studia Slavica Hung. 46 (2001): 305-316.

Орос $2017=$ Орос А. Ареальные вопросы страдательного залога в языках Северной Европы и в севернорусском диалекте. Вестник Филиала Института русского языка им. А. С. Пушкина. № 31. Будапешт, 2017. 270-275.

ОРОс $2018 \mathrm{a}=$ ОРос А. О статусе страдательного залога в севернорусском диалекте. В кн.: Русистика и современность. Часть 1. Санкт-Петербург: «Северная звезда», 2018. 130-135.

ОРос $2018 b$ = ОРос А. Подлежащее как самостоятельный член предложения и его роль в появлении или исчезновении страдательного залога в различных языках. Вестник Филиала Института русского языка им. А. С. Пушкина. № 32. Будапешт, 2018. 208-212.

Труьинский 1984 = ТруБинский В. И. Очерки русского диалектного синтаксиса. Ленинград: Издательство Ленинградского университета, 1984.

ХРАКОВСКИЙ 1974 = ХРАКОВСКИй В. С. Пассивные конструкции. В кн.: Типология пассивных конструкиий. Диатезы и залоги. Ленинград: «Наука», 1974. 5-45.

DRINKA $2003=$ DRINKA B. Areal factors in the development of the European periphrastic perfect. Word 54 (2003): 1-38.

DrINKA 2017 = DRINKA B. Language Contact in Europe. Cambridge: Cambridge University Press, 2017.

Holvoet 2001 = Holvoet A. Impersonals and passives in Baltic and Fennic. In: Dahl Ö., Koptjevskaja-Tamm M. (ed.) Circum-Baltic Languages. Vol. 2. Grammar and Typology. Amsterdam-Philadelphia: John Benjamins, 2001. 363-389.

KeEnAN 1976 = KeEnAN E. L. Towards a universal definition of 'subject'. In: Li C. N. (ed.) Subject and Topic. New York: Academic Press, 1976. 303-333.

KLAIMAN 1988 = KLAIMAN M. H. Affectedness and control: a typology of voice systems. In: Shibatani M. (ed.) Passive and Voice. Amsterdam-Philadelphia: John Benjamins, 1988. 25-83.

Klaiman 1991 = Klaiman M. H. Grammatical Voice. Cambridge: Cambridge University Press, 1991.

Orosz 2002 = Orosz Árpád: A szenvedö szerkezetek dinamikus és statikus értelmezése az orosz nyelvben, a magyar és az angol nyelv tükrében [Акциональное и статальное истолкование страдательных конструкций в русском языке, в зеркале венгерского и английского языков]. Кандидатская диссертация. Budapest: ELTE BTK, 2002.

Orosz 2012 = Orosz Árpád: A szenvedő szerkezetek kialakulásáról. Összhangban a gondolkodás változásával [О формировании страдательных конструкций. В взаимосвязи с изменением мышления]. Élet és Tudomány 2012/26: 809-811.

SERŽANT 2012 = SERŽANT I. A. The so-called possessive perfect in North Russian and the Circum-Baltic area. A diachronic and areal account. Lingua 122 (2012): 356-385.

SERŽANT 2013 = SERŽANT I. Rise of canonical subjecthood. In: SeržAnt I., Kulikov L. (ed.) The Diachronic Typology of Non-Canonical Subjects. Amsterdam-Philadelphia: John Benjamins, 2013. 283-310.

Timberlake 1976 = Timberlake A. Subject properties in the North Russian passive. In: Li C. N. (ed.) Subject and Topic. New York: Academic Press, 1976. 547-570. 


\author{
ÁRPÁD OROSZ \\ Department of Languages for Finance and Business, Faculty of Finance \\ and Accountancy, Budapest Business School
}

\title{
On Passive Voice in Languages Spoken in the Baltic Sea Region with an Emphasis on North Russian Dialect
}

The two characteristics of the passive voice found in the North Russian dialect and in other Circum-Baltic languages, the accusative case of the patient or theme as an argument of a verb with passive morphology and intransitive verbs passivized raise a number of related questions. The author of the present paper explores the issues under discussion from an areal-historical perspective, concluding that the aforementioned languages have a tendency for the agent to be the same element as the subject and the patient or theme to be the same element as the (direct) object of the sentence. In the North Russian dialect, we can see an example where the above fact holds true irrespective of whether the verb has an active or a passive morphology as the theme of the sentence assumes the accusative case regardless of whether it is an argument of a verb in the active or in the passive voice.

The question as to what lexical elements can function as subjects is itself interesting. Moreover, there seems to be a correlation between what level of abstraction the syntactic category of subject has reached in a language and the existence of a pure passive meaning. The less abstract the category of subject is, as in case of Circum-Baltic languages, the farther structures with a passive morphology seem to be from a pure passive meaning. In languages such as English, however, where virtually any noun can function as a subject, there seems to be a pure passive meaning and there is only one morphological way of forming passive sentences.

The nature of linguistic similarities found in genetically less related languages spoken in the same area has been given a number of varied accounts. The most salient of them appears to be B. Drinka's explanation based on the influence of Western European languages on ones spoken in the East of the area where once the Hanseatic League existed in the middle ages and I. Seržant's theory concerning the foregrounding of the agent as passive structures with a stative interpretation gradually assumed a dynamic one.

In fact, participles in the North Russian dialect ending in $-n /-t$ can express a dynamic, that is, eventive interpretation with a perfect meaning and can even co-occur with the -sja/-s' postfix, the latter phenomenon being absolutely unimaginable in Standard Russian, where the two affixes are in complementary distribution. The author assumes that the topic should be studied from the perspective of sociology and cultural anthropology as well since linguistic similarities and differences often reflect similarities and differences in thinking beyond the realm of linguistics.

Keywords: Circum-Baltic languages, areal linguistics, active voice, passive voice, subjecthood, past passive participles, North Russian dialect, Hanseatic League

Open Access. This is an open-access article distributed under the terms of the Creative Commons Attribution 4.0 International License (https://creativecommons.org/licenses/ by/4.0), which permits unrestricted use, distribution, and reproduction in any medium, provided the original author and source are credited, a link to the CC License is provided, and changes - if any - are indicated. (SID_1) 